
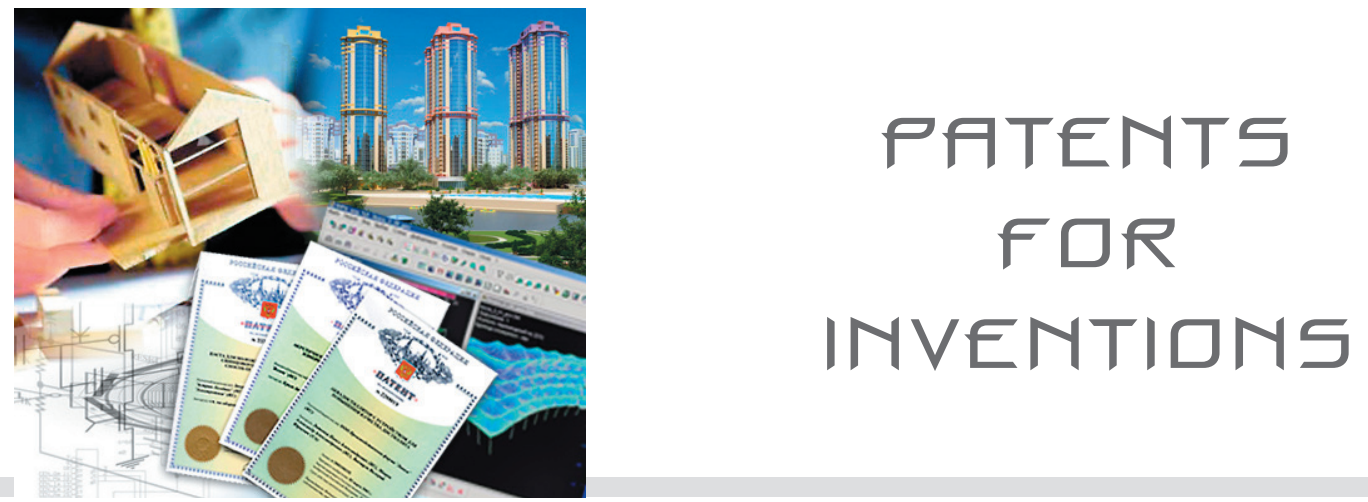

UDC 62; 69

VLASOV Vladimir Alexeevich, Ph.D. in Engineering, Expert, International Academy of Engineering;

Gazetny per., block 9, bld.4, Moscow, 125009, Russian Federation, e-mail: info@nanobuild.ru

\title{
THE NANOTECHNOLOGICAL INVENTIONS RAISE COMPETITIVE ABILITY OF THE PRODUCTS
}

A brief description of the nanotechnological inventions is given. The inventions in the area of nanotechnologies and nanomaterials produce a profound effect in construction, housing and communal services and adjacent economic fields as they allow us: to obtain high strength and durability of surfaces of the details, to provide different materials with hydrophil properties, to increase efficiency of transformation of light energy into electrical one etc., and in general - to raise competitive ability of the products. For example, the method of production of solar element and a unit of solar elements (RU 2532137) comprises following stages: formation of pn-transfer in semiconductor base plate, formation of passivating layer on the light-receptive surface and/or non light-receptive surface of semiconductor base plate and formation of power robbing electrodes on the light-receptive surface and non light-receptive. A film of aluminium oxide is formed as passivating layer, its thickness is up to $40 \mathrm{~nm}$, and electrode is formed by baking conductive paste under the temperature $500-900^{\circ} \mathrm{C}$ for 1 second -30 minutes with formation of sintered product. The sintered product penetrates through passivating layer setting electric contact between electrode and base plate. The formation of aluminium oxide with specified thickness on the surface of base plate makes it possible to achieve good passivating characteristics and good electric contact between silica and electrode only by means of baking conductive paste, that is standard technology. Moreover the baking stage which was necessary to get the effect of film passivation for aluminium oxide in the past now can be cancelled to decrease costs. 
The specialists may be also interested in the following nanotechnological inventions: reinforced flaked element made of natural or conglomerate stone and its multilayer protective coating (RU 2520193); fine organic suspension of carbon metal-containing nanostructures and the method to produce it (RU 2515858); the method of production of carbon nanomaterial (RU 2509053); the method to produce nanopowder of zinc oxide with the surface modification for the use in construction sealing materials ( $R U$ 2505379); building structures reinforcement composition (RU 2493337); nanostructured thermoelectric material (RU 2528338); conglutination composition for metal articles (RU 2526991); the method of nanosize structures formation структур (RU 2529458) etc.

Key words: nanotechnologies, nanomaterials, nanocomposites, nanocomposites, nanostructures, nanotubes, nanoparticles, nanopowders.

\section{Polymer copper-containing composite and the method to produce it (RU 2528981)}

The invention refers to nanotechnologies, more exactly to material and production technology for spherical aggregations containing nanosize particles (NSP) of metal, in particular copper, in the cover of another substance or organic polymer. It is possible to produce individual NSP as well as component parts of nanocomposites including those which contain polymers. The invention concerns the method to produce polymer copper-containing composite which consists of homogenous spherical polymer aggregations (diameter is 50-200 $\mathrm{nm}$ ) with introduced spherical copper nanoparticles which diameter is $5-10 \mathrm{~nm}$. The invention also refers to the method of production of polymer copper-containing composite which provides for the thermal decomposition of polymer predecessor under the temperature $450^{\circ} \mathrm{C}$ in inert atmosphere. The technical result is production of composite made of homogenous spherical aggregations containing numerous copper nanoparticles introduced in polymer matrix with the short range of size distribution [1]. 


\section{The method for modification of carbon nanotubes (RU 2528985)}

The invention can be used to produce modified carbon nanotubes. The method for modification of carbon nanotubes includes treatment of carbon nanotubes with aqueous solution of oxidizer (solution of persulfate or гипохлорита when ph is more than 10) carried out along with mechanical treatment. The invention allows obtaining modified carbon nanotubes with good dispersive ability in water and polar organic dissolvents by small reagent consumption compared with known methods [2].

\section{Solar element, the method of production of solar element and unit of solar elements}

(RU 2532137)

The method of production of solar element and a unit of solar elements comprises following stages: formation of pn-transfer in semiconductor base plate, formation of passivating layer on the light-receptive surface and/or non light-receptive surface of semiconductor base plate and formation of power robbing electrodes on the light-receptive surface and non light-receptive. A film of aluminium oxide is formed as passivating layer, its thickness is up to $40 \mathrm{~nm}$, and electrode is formed by baking conductive paste under the temperature $500-900^{\circ} \mathrm{C}$ for 1 second -30 minutes with formation of sintered product. The sintered product penetrates through passivating layer setting electric contact between electrode and base plate. The formation of aluminium oxide with specified thickness on the surface of base plate makes it possible to achieve good passivating characteristics and good electric contact between silica and electrode only by means of baking conductive paste, that is standard technology. Moreover the baking stage which was necessary to get the effect of film passivation for aluminium oxide in the past now can be cancelled to decrease costs [3].

\section{The method of production of ceramic slurry (RU 2531960)}

The method refers to powder metallurgy and can be applied for moulding products with the use of thermoplastical slurry casting as well as with 
direct moulding injecting through nozzles. The method of production of ceramic slurry provides increased flow characteristics under low temperatures and resistance to thermal impacts. The method includes mixing of dispersed powders of metal oxides and organic bundle. 12-18 mass. \% of organic bundle (bee wax or paraffin) taken in the form of solid solutions of metal oxides are added in dispersed powder, then the temperature of mass is increased up to $80-90^{\circ} \mathrm{C}$, molten mixture (consists of stearic acid and ethylene vinyl acetate taken in mass ratio $1 / 4-1 / 3$, quantity $5-6$ mass. $\%$ of organic bundle mass) is added and further the obtained mass is mixed within 2 hours under the temperature $80-90^{\circ} \mathrm{C}$ till it is ready [4].

\section{The method to provide different materials with hydrophilic properties by means of organic siloxane coating with nitrilotrimethylenphosphonic acid (RU 2531818)}

The invention refers to manufacture of modified materials, such as fiber, polymer, made of silicate glass, wood, leather, metal, ceramics and can be used to provide surfaces of these materials with hydrophilic properties. To provide materials of differen nature with hydrophilic properties modifier is applied on the surface. The coating is formed through consistent application of water solution of oligo (aminopropyl) ethoxysilane and further application of water solution of nitrilotrimethylenphosphonic acid. Having applied each solution, open air drying and thermal treatment are made. The invention provides different materials with high hydrophilic properties [5].

\section{Tandem solar phototransformer (RU 2531767)}

The invention refers to the area of solar photo power systems, in particular to the devices for direct transformation of solar energy into electric one. The offered tandem solar phototransformer contains two solar elements (one is over another), the upper one is a metal-oxide solar element based on mesoscopic layer of sensitized metal oxide and the lower one is a solid solar element. The thickness of mesoscopic layer of sensitized metal oxide is $5.0-5.5 \mu \mathrm{m}$, and as a lower solid solar element phototransformer employs solar element based on mono- and multicrystal silica, the differ- 
ence between tension of free movement in upper and lower solar elements of phototransformer doesn't exceed $0,1 \mathrm{~V}$, and parallel electric connection to the current sink of the upper and lower solar elements is performed. As mesoscopic layer of sensitized metal oxide one can use sensitized nanocrystal metaloxide selected from the group: titanium dioxide, zinc oxide, nickel oxide, ferric oxide and mixture of them. The described phototransformer performs direct transformation of light energy into electrical one and doesn't depend on the intensivity of solar radiation and angle of light incidence and increses efficiency of transformation of light energy into electric including conditions of weak and diffuse illumination [6].

\section{The method to obtain soot containing fullerens and nanotubes from gaseous carbon stuff \\ (RU 2531291)}

The invention refers to the area of plasma chemistry and can be used to produce fulleres and nanotubes. Carbon-containing stuff is decomposed in gas discharge, for that at first volume smouldering discharge is allowed in the mixture of gaseous hydrocarbons and inert gas under the pressure 20$80 \mathrm{~mm} \mathrm{Hg}$. Then performing visual analysis it is necessary to make smouldering discharge burn with constricted cathode zone and diffuse positive column. The decomposed products are precipitated in the form of soot. The performance of the process in highly nonequilibrium discharge allows increasing soot production rate and increasing nanotubes and fullerens outcome per unit of spent energy 9,6 times [7].

\section{Dispersion of carbon nanotubes (RU 2531171)}

The invention can be used to produce composites which contain organic polymer. Dispersion of carbon nanotubes contains 1 part by weight. of oxidized carbon nanotubes and $0,25-10$ parts by weight. of the product which appers as a result of interaction between organic amine (its molecule possesses at least one hydroxyl group and at least amine group) with tetraallylsilane. Dispersion is stable under high mass content of the nanotubes and minimal content of ballast substances [8]. 


\section{The method of ultrasound final polishing of the details made of constructional and tool steels and the device to perform this method (RU 2530678)}

The invention refers to mechanical engineering, in particular to final polishing of the details. The detail is rotated and its surface is exposed to ultrasound final polishing performed by the device with deforming element. The device for final polishing with deforming element is moved along the detail with specified ultrasound oscillation and repeated impact polishing is performed with the deforming element which ultrasound frequency is about $20 \mathrm{kHz}$ and amplitude $5-40 \mu \mathrm{m}$. The deforming element and the detail are partially immersed in the bath with kerosene to cool the treated surface of the detail and to obtain gradient submicro- and nanocrystal structures. That results in high strength and hardness of detail surface [9].

\section{The method to produce flaked nanomaterial (RU 2530456)}

The invention refers to the methods for production of flaked nanomaterials based on semiconductors, dielectric and metals and can be used to manufacture some functional materials or metastable phase-precursors of these materials. It is important both for improving production technology of these materials (as well as for articles and devices based on them) and improving properties of these materials. The method causes improved consumer properties of the materials, articles and devices and that leads to increased competitive ability of industrial products, in particular construction materials, machinery and electronics products [10].

\section{The method of application of nanodiamond material by means of combined electromechanical treatment (RU 2530432)}

The invention refers to the method of application of nanodiamond material by means of combined electromechanical treatment and can be used in mechanical engineering and other industries. The treatment is performed under normal atmosphere conditions, the friction surface of steel details is coated with luting which consists of curdling nanodiamonds in the form 
of powder which size is $200-250 \mathrm{~nm}$, mixed with consistent graphite lubricant and then electromechanical treatment is performed providing surface layer of steel with ferrite-sorbitic and fine pearlite structure and forming nanostructural layer of graphite baked with nanodiamonds to obtain common strengthen layer with thickness up to $1,2 \mathrm{~mm}$ on the surface of steel. Thus tribotechnical characteristics and wear resistance of coated details are increased [11].

The specialists may be also interested in the following nanotechnological inventions:

- Reinforced flaked element made of natural or conglomerate stone and its multilayer protective coating (RU 2520193) [12];

- Fine organic suspension of carbon metal-containing nanostructures and the method to produce it (RU 2515858) [12];

- The method of production of carbon nanomaterial (RU 2509053) [13];

- The method of production of nanodispersed metal powders and alloys of them (RU 2509626) [13];

- The method to produce nanopowder of zinc oxide with the surface modification for the use in construction sealing materials (RU 2505379) [14];

- The method to produce polymer composition (RU 2506283) [14];

- The method of dispersion of nanoparticles in epoxy resin (RU 2500706) [15];

- The method to produce nanosuspension for manufacturing polymer nanocomposite (RU 2500695) [15];

- Dispersion of Carbon Nanotubes (RU 2494961) [16];

- $\quad$ Building Structures Reinforcement Composition (RU 2493337) [16];

- $\quad$ Nanostructured thermoelectric material (RU 2528338) [17];

- The method of production of absorbing coating for solar heating, coating and its application (RU 2528486) [18];

- The method of production of flaky material (RU 2528581) [19];

- The method of production of modifier for aluminium alloys (RU 2528598) [20];

- The method of production of composite materials based on silicon oxide (RU 2528667) [21]; 
- The method of production of nanosize lithium titanate powder (RU 2528839) [22];

- The modification method for carbon nanotubes (RU 2528985) [23];

- Conglutination composition for metal articles (RU 2526991) [24];

- Thin dispersed organic suspension of metal/carbon nanocomposite and the production method for it (RU 2527218) [25];

- The method for strengthening metal products with nanostructured surface layers (RU 2527511) [26];

- The method to produce graphene structures (RU 2530084) [27].

- The method for formation of nanosize structures (RU 2529458) [28].

DeAr COlleagues!

THE REFERENCE TO THIS PAPER HAS THE FOLLOWING CITATION FORMAT:

Vlasov V.A. The nanotechnological inventions raise competitive ability of the products. Nanotehnologii v stroitel'stve = Nanotechnologies in Construction. 2014, Vol. 6, no. 6, pp. 58-78. DOI: dx.doi.org/10.15828/2075-8545-2014-6-6-58-78 


\section{References:}

1. Patents and inventions registered in RF and USSR [Electronic source]. - Access mode: http://www.findpatent.ru/patent/252/2528981.html (date of access: 22.10.14).

2. Patents and inventions registered in RF and USSR [Electronic source]. - Access mode: http://www.findpatent.ru/patent/252/2528985.html (date of access: 22.10.14).

3. Patents and inventions registered in RF and USSR [Electronic source]. - Access mode: http://www.findpatent.ru/patent/253/2532137.html (date of access: 22.10.14).

4. Patents and inventions registered in RF and USSR [Electronic source]. - Access mode: http://www.findpatent.ru/patent/253/2531960.html (date of access: 22.10.14).

5. Patents and inventions registered in RF and USSR [Electronic source]. - Access mode: http://www.findpatent.ru/patent/253/2531818.html (date of access: 22.10.14).

6. Patents and inventions registered in RF and USSR [Electronic source]. - Access mode: http://www.findpatent.ru/patent/253/2531767.html (date of access: 22.10.14).

7. Patents and inventions registered in RF and USSR [Electronic source]. - Access mode: http://www.findpatent.ru/patent/253/2531291.html (date of access: 22.10.14).

8. Patents and inventions registered in RF and USSR [Electronic source]. - Access mode: http://www.findpatent.ru/patent/253/2531171.html (date of access: 22.10.14).

9. Patents and inventions registered in RF and USSR [Electronic source]. - Access mode: http://www.findpatent.ru/patent/253/2530678.html (date of access: 22.10.14).

10. Patents and inventions registered in RF and USSR [Electronic source]. - Access mode: http://www.findpatent.ru/patent/253/2530456.html (date of access: 22.10.14).

11. Patents and inventions registered in RF and USSR [Electronic source]. - Access mode: http://www.findpatent.ru/patent/253/2530432.html (date of access: 22.10.14).

12. Vlasov V.A. Inventions in the nanotechnological area considerably increase wear- and chemical resistance of construction products. Nanotehnologii v stroitel'stve $=$ Nanotechnologies in Construction. 2014, Vol. 6, no. 4, pp. 66-88. Available at: http://nanobuild.ru/ en_EN/ (date of access: 22.10.14). (In Russian).

13. Vlasov V.A. Nanotechnological inventions considerably improve performance characteristics of concretes, polymers, metals and other materials. Nanotehnologii v stroitel'stve $=$ Nanotechnologies in Construction. 2014, Vol. 6, no. 3, pp. 77-95. Available at: http:// nanobuild.ru/en_EN/(date of access: 22.10.14). (In Russian).

14. Vlasov V.A. Inventions in the nanotechnological area provide improved performance characteristics of different sealing polymer materials used in construction. Nanotehnologii v stroitel'stve $=$ Nanotechnologies in Construction. 2014, Vol. 6, no. 2, pp. 78-107. Available at: http://nanobuild.ru/en_EN/(date of access: 22.10.14). (In Russian).

15. Vlasov V.A. Inventions in the nanotechnological area provide increased resistance of construction materials and products to operationalload. Nanotehnologii v stroitel'stve $=$ Nanotechnologies in Construction. 2014, Vol. 6, no. 1, pp. 68-90. Available at: http://nanobuild.ru/en_EN/(date of access: 22.10.14). (In Russian). 
16. Vlasov V.A. Inventions in the nanotechnological area provide increased resistance of construction materials and products to operational load. Nanotehnologii v stroitel'stve $=$ Nanotechnologies in Construction. 2013, Vol. 5, no. 6, pp. 126-140. Available at: http:// nanobuild.ru/en_EN/ (date of access: 22.10.14). (In Russian).

17. Patents and inventions registered in RF and USSR [Electronic source]. - Access mode: http://www.findpatent.ru/patent/252/2528338.html (date of access: 22.10.14).

18. Patents and inventions registered in RF and USSR [Electronic source]. - Access mode: http://www.findpatent.ru/patent/252/2528486.html (date of access: 22.10.14).

19. Patents and inventions registered in RF and USSR [Electronic source]. - Access mode: http://www.findpatent.ru/patent/252/2528581.html (date of access: 22.10.14).

20. Patents and inventions registered in RF and USSR [Electronic source]. - Access mode: http://www.findpatent.ru/patent/252/2528598.html (date of access: 22.10.14).

21. Patents and inventions registered in RF and USSR [Electronic source]. - Access mode: http://www.findpatent.ru/patent/252/2528667.html (date of access: 22.10.14).

22. Patents and inventions registered in RF and USSR [Electronic source]. - Access mode: http://www.findpatent.ru/patent/252/2528839.html (date of access: 22.10.14).

23. Patents and inventions registered in RF and USSR [Electronic source]. - Access mode: http://www.findpatent.ru/patent/252/2528985.html (date of access: 22.10.14).

24. Vlasov V.A. The inventions in nanotechnological area increase the efficiency of construction, housing and communal services and adjacent economic fields. Nanotehnologii v stroitel'stve $=$ Nanotechnologies in Construction. 2014, Vol. 6, no. 5, pp. 93-113. DOI: dx.doi.org/10.15828/2075-8545-2014-6-5-93-113.

25. Patents and inventions registered in RF and USSR [Electronic source]. - Access mode: http://www.findpatent.ru/patent/253/2530084.html (date of access: 22.10.14).

26. Patents and inventions registered in RF and USSR [Electronic source]. - Access mode: http://www.findpatent.ru/patent/252/2529458.html (date of access: 22.10.14). 